\title{
FUNGOS MICORRÍZICOS ARBUSCULARES E ADUBAÇÃO FOSFATADA NA PRODUÇÃO DE MUDAS DE PARICÁ
}

\section{ARBUSCULAR MYCORRHIZAL FUNGI AND PHOSPHATE FERTILIZATION ON THE SEEDLING PRODUCTION OF PARICÁ}

\author{
Vanessa Nascimento Brito ${ }^{1}$ Fernando Reynel Fundora Tellechea ${ }^{2}$ Letícia Celia Heitor $^{3}$ \\ Marta Simone Mendonça Freitas ${ }^{4}$ Marco Antonio Martins $^{5}$
}

\begin{abstract}
RESUMO
A recuperação de diferentes ecossistemas degradados demanda pesquisas com espécies florestais nativas que possam subsidiar programas de recuperação florestal. A produção de mudas com espécies arbóreas nativas em associação com os microrganismos do solo é uma importante técnica para a reabilitação desses ambientes. O presente trabalho teve como objetivo avaliar os efeitos da inoculação com fungos micorrízicos arbusculares (FMAs) e nutrição fosfatada sobre o crescimento e conteúdos nutricionais de mudas de paricá [Schizolobium parahyba var. amazonicum (Huber ex Ducke) Barneby]. O experimento casa de vegetação por um período de 75 dias, utilizando-se o delineamento experimental inteiramente casualizado, em esquema fatorial 4 × 4, inoculação com os FMAs: Rhizophagus clarus, Gigaspora margarita, inóculo misto (Rhizophagus clarus + Gigaspora margarita) e controle (sem FMAs); quatro doses de P: 0, 60, 120 e $180 \mathrm{mg} \mathrm{dm}^{-3}$ de solo, com quatro repetições. Foram avaliadas as variáveis altura, matéria seca da parte área (MSPA), matéria seca da raiz (MSR), área foliar (AF), diâmetro do coleto (DC) e os conteúdos de N, $\mathrm{P}, \mathrm{K}, \mathrm{Ca}$ e Mg na parte aérea. As mudas de paricá apresentaram maior porcentagem de colonização para Rhizophagus clarus e o inóculo misto ( 80 e $90 \%$, respectivamente), diferentemente do observado para a espécie Gigaspora margarita, com menor porcentagem (20\%). O Rhizophagus clarus e o inóculo misto, na ausência de $\mathrm{P}$, propiciaram incremento para as variáveis de crescimento em relação ao controle. Os conteúdos de N, P, Ca e Mg foram influenciados pelos FMAs e pelas doses de $\mathrm{P}$.
\end{abstract}

Palavras-chave: micorrizas; fósforo; paricá; espécie florestal.

\section{ABSTRACT}

The recovery of degraded ecosystems demands research with native species that can support forest restoration programs. The production of seedlings with native tree species in association with soil microorganisms is an important technique for the rehabilitation of these environments. This study aimed to evaluate the effects of inoculation with arbuscular mycorrhizal fungi (AMF) and phosphorus nutrition on growth and nutrient content of paricá seedlings [Schizolobium parahyba var. amazonicum (Huber ex Ducke) Barneby]. The experiment was conducted in a greenhouse for a period of 75 days, using a completely randomized design in a factorial 4x4, inoculation with AMF: Rhizophagus clarus, Gigaspora margarita, mixed inoculum

1 Engenheira Agrônoma, MSc., Doutoranda do Programa de Pós-graduação em Microbiologia Agrícola, Universidade Federal de Viçosa, Campus Universitário, CEP 36570-900, Viçosa (MG), Brasil. vanessa.brito@ufv.br

2 Engenheiro Agrônomo, MSc., Doutorando do Programa de Pós-graduação em Produção Vegetal, Universidade Estadual do Norte Fluminense Darcy Ribeiro, 2000, CEP 28013-602, Campos dos Goytacazes (RJ), Brasil. fundotell@gmail.com

3 Engenheira Agrônoma, MSc., Doutoranda do Programa de Pós-graduação em Produção Vegetal, Universidade Federal do Espírito Santo, s/n, CEP 29500-000, Alegre (ES), Brasil. leticiac_heitor@yahoo.com.br

4 Graduada em Ciências, Dra ., Professora Associada do Laboratório de Fitotecnia, Universidade Estadual do Norte Fluminense Darcy Ribeiro, 2000, CEP 28013-602, Campos dos Goytacazes (RJ), Brasil.msimone@uenf.br

5 Engenheiro Agrônomo, Dr., Professor Titular do Laboratório de Solos, Universidade Estadual do Norte Fluminense Darcy Ribeiro, 2000, CEP 28013-602, Campos dos Goytacazes (RJ), Brasil. marco@uenf.br

Recebido para publicação em 5/10/2013 e aceito em 15/09/2015 
(Rhizophagus clarus + Gigaspora margarita) and control (without AMF), four P doses: 0, 60, 120 and 180 $\mathrm{mg} \mathrm{dm}{ }^{-3}$ soil, with four replications. The variables height, dry matter area, root dry matter, leaf area, stem diameter and the contents of $\mathrm{N}, \mathrm{P}, \mathrm{K}, \mathrm{Ca}$ and $\mathrm{Mg}$ in shoots, were evaluated. Paricá seedlings showed higher colonization percentage for Rhizophagus clarus and mixed inoculum (80 and 90\%, respectively), different from that observed for the species Gigaspora margarita, with a lower percentage (20\%). The Rhizophagus clarus and mixed inoculum, in the absence of $\mathrm{P}$, increased the growth variables relative to the control plants. The contents of N, P, Ca and Mg were influenced by the AMF and by the doses of P.

Keywords: mycorrhizas; phosphorus; paricá; forest species.

\section{INTRODUÇÃO}

O Brasil possui a maior área de floresta do mundo, com cerca de $40 \%$ da cobertura florestal tropical do planeta (INSTITUTO DO HOMEM E MEIO AMBIENTE DA AMAZÔNIA, 2011), destacando-se a região amazônica, em razão da elevada biodiversidade e da reconhecida importância como fornecedora de produtos e serviços ambientais nacional e internacionalmente. No entanto, os índices de desmatamento registrados nessa região evidenciam a transformação de áreas de florestas naturais para a produção de alimentos e/ou exploração madeireira. De acordo com a Política Nacional do Meio Ambiente (Lei 6.938/81) é necessário que se faça a recuperação de áreas degradadas em prol da proteção do meio ambiente (BRASIL, 1981). Dentre as estratégias adotadas faz-se o uso da revegetação com espécies arbóreas, que são importantes para a recuperação das características físicas, químicas e biológicas do solo (MOREIRA; SIQUEIRA, 2006). No ano de 2012, foi aprovada a Lei 12.727, denominada de "Novo Código Florestal" que levou ao aumento da demanda por sementes e mudas de espécies florestais nativas para recuperação ou recomposição de Áreas de Preservação Permanente (APP) e Reserva Legal (RL) (LEÃO et al., 2015).

A maioria das espécies florestais nativas é pouco estudada, havendo necessidade de subsídios científicos que promovam produção de mudas em grande quantidade e com qualidade, facilitando desta forma o manejo e o custo de produção, principalmente de espécies de grande interesse comercial como é o caso do paricá. O paricá [Schizolobium parahyba var. amazonicum (Huber ex Ducke) Barneby] é uma leguminosa nativa da Amazônia, pertencente à família Caesalpiniaceae, utilizada na fabricação de laminados e compensados por apresentar madeira leve (SABOGAL et al., 2006). Além disso, essa espécie vem sendo intensamente utilizada nos programas de reflorestamento por apresentar rápido crescimento, valor comercial, plasticidade para se adaptar em diversas condições edafoclimáticas (ROSA et al., 2006; LUNZ et al., 2010; GONDIN et al., 2015) e ser considerada uma espécie energético-madeireiro utilizada rápido crescimento, valor comercial, plasticidade para se adaptar em diversas condições edafoclimáticas (ROSA et al., 2006; LUNZ et al., 2010) e ser considerada uma espécie energético-madeireiro utilizada em sistemas agroflorestais no estado do Pará (BRIENZA JÚNIOR et al., 2008). Entretanto, poucos são os estudos de paricá com fungos micorrízicos arbusculares (FMAs).

Nas últimas décadas vem ocorrendo o reconhecimento da importância funcional e ecológica da simbiose dos FMAs com as plantas (CARNEIRO et al., 2011), devido a esses microrganismos serem benéficos no solo, junto ao vegetal, aumentando o nível de tolerância a situações de estresse abiótico (BAREA et al., 2013). Contudo, apesar dos FMAs serem de ocorrência generalizada nos ecossistemas tropicais, pesquisas sobre as relações entre este simbionte e seus hospedeiros são insuficientes para espécies arbóreas (FARIAS et al., 2013).

Os FMAs associados às plantas hospedeiras aumentam a área da superfície da raiz e permitem maior capacidade de absorção de água e nutrientes do solo, proporcionando maior taxa de crescimento e sobrevivência (NADEEM et al., 2014). Durante a interação micorrízica, as plantas utilizam nutrientes absorvidos pelos FMAs, principalmente o fósforo (P), e esses por sua vez, utilizam produtos oriundos da fotossíntese realizada pelas plantas (WALDER et al., 2012). Schiavo et al. (2009) observaram que mudas de espécies florestais produzidas em casa de vegetação e inoculadas com os FMAs apresentaram maior crescimento e qualidade. Lacerda et al. (2011), trabalhando com mudas de caroba (Jacaranda cuspidifolia), observaram efeito significativo da inoculação com FMA, da aplicação de P e da interação entre esses fatores na produção da matéria seca da parte aérea (MSPA), evidenciando um sinergismo entre a aplicação de $\mathrm{P}$ e inoculação com Rhizophagus clarus (= Glomus clarum) no crescimento das plantas. 
Em estudos com FMAs e espécies arbóreas é necessário avaliar diferentes dosagens de P para otimizar o crescimento e a nutrição das plantas, pois a associação fungo-hospedeiro mediada por diferentes dosagens de fósforo variam com as espécies envolvidas (SAMARÃO et al., 2011), bem como, essa interação pode aumentar ou diminuir de acordo com a disponibilidade de P no solo (YANG et al., 2014). Segundo Vieira et al. (2006), a adubação com fósforo é um fator importante no crescimento do paricá em fase de muda. Viégas et al. (2007), também trabalhando com esta espécie, observaram que a adubação fosfatada influenciou de forma significativa no desenvolvimento e volume comercial da madeira.

Diante do exposto, esse trabalho teve como objetivo avaliar o efeito de fungos micorrízicos arbusculares e diferentes doses de fósforo sobre o crescimento e conteúdos de nitrogênio, fósforo, potássio, cálcio e magnésio na parte aérea de mudas de paricá.

\section{MATERIAIS E MÉTODOS}

O experimento foi realizado em casa de vegetação na Universidade Estadual do Norte Fluminense Darcy Ribeiro (UENF), por 75 dias, entre os meses de novembro a janeiro de 2012/2013. As espécies de FMAs utilizadas Rhizophagus clarus (NICOLSON et al., 2010), Gigaspora margarita (BECKER; HALL, 1976) e inóculo misto (Rhizophagus clarus + Gigaspora margarita) foram provenientes do Banco de Inóculo do Setor de Microbiologia do Solo, Laboratório de Solos, da UENF. O substrato para a produção das mudas foi composto de mistura de solo (Latossolo Amarelo predominantemente argiloso, coletado da camada de 0 a $20 \mathrm{~cm}$ de profundidade) e areia na proporção de $1: 1(\mathrm{v} / \mathrm{v})$, esterilizado em autoclave por 2 horas, a uma temperatura de $121^{\circ} \mathrm{C}$. Após a esterilização foi realizada a análise química do substrato, que apresentou as seguintes características químicas: $\mathrm{pH}\left(\mathrm{H}_{2} \mathrm{O}\right)=5,7 ; \mathrm{MO}=16,03 \mathrm{~g} \mathrm{dm}^{-3} ; \mathrm{P}=15,0 \mathrm{mg} \mathrm{dm}^{-3} ; \mathrm{S}=6,0$ $\mathrm{mg} \mathrm{dm}{ }^{-3} ; \mathrm{K}=2,1 \mathrm{mmol}_{\mathrm{c}} \mathrm{dm}^{-3} ; \mathrm{Ca}=12,2 \mathrm{mmol}_{\mathrm{c}} \mathrm{dm}^{-3} ; \mathrm{Mg}^{2}=8,0 \mathrm{mmol} \mathrm{dm}_{\mathrm{c}}^{-3} ; \mathrm{Al}=0,0 \mathrm{mmol}_{\mathrm{c}} \mathrm{dm}^{-3} ; \mathrm{H}+\mathrm{Al}=13,1$ $\mathrm{mmol}_{\mathrm{c}} \mathrm{dm}^{-3} ; \mathrm{Na}=1,1 \mathrm{mmol}_{\mathrm{c}} \mathrm{dm}^{-3} ; \mathrm{SB}=23,40 \mathrm{mmol}_{\mathrm{c}} \mathrm{dm}^{-3} ; \mathrm{CTC}=36,5 \mathrm{mmol}_{\mathrm{c}} \mathrm{dm}^{-3} ; \mathrm{Fe}=114,22 \mathrm{mg} \mathrm{dm}^{-3} ; \mathrm{Cu}=$ $0,31 \mathrm{mg} \mathrm{dm}^{-3} ; \mathrm{Zn}=3,49 \mathrm{mg} \mathrm{dm}^{-3} ; \mathrm{Mn}=32,81 \mathrm{mg} \mathrm{dm}^{-3}$ e B=0,37 $\mathrm{mg} \mathrm{dm}^{-3}$. Posteriormente, foram aplicadas as doses de $\mathrm{P}$, utilizando-se como fonte $\mathrm{KH}_{2} \mathrm{PO}_{4}$ e $\mathrm{NaH}_{2} \mathrm{PO}_{4}$ para os tratamentos com fósforo. Os teores de $\mathrm{K}$ do substrato foram elevados para $120 \mathrm{mg} \mathrm{dm}^{-3}$ por meio do fornecimento de $\mathrm{KH}_{2} \mathrm{PO}_{4}$ e $\mathrm{KCl}$ para todos os tratamentos da dose 0 de P. Posteriormente à correção, o substrato foi distribuído nos vasos, umedecidos $\mathrm{e}$ incubados por um período de 15 dias. Aos 30 e 60 dias após o plantio aplicou-se uma dose de $10 \mathrm{mg} \mathrm{dm}^{-3}$ de $\mathrm{N}$ por kg de solo, utilizando-se como fonte nitrato de amônio $\left(\mathrm{NH}_{4} \mathrm{NO}_{3}\right)$, para todos os tratamentos.

Para a multiplicação do inóculo foram utilizadas sementes de milho (Zea mays L.) e após o plantio, os vasos foram mantidos em casa de vegetação por um período de 60 dias para a multiplicação dos fungos. Posteriormente, a parte aérea foi podada e os vasos foram cobertos com folhas de papel e mantidos sem irrigação, por um mês, para estimular a esporulação dos fungos. Transcorrido este período, a mistura do solo contendo raízes colonizadas e esporos dos FMAs, foi utilizada como inóculo, sendo conservados em câmara fria a $4^{\circ} \mathrm{C}$ até a instalação do experimento.

As sementes de paricá foram adquiridas na Associação das Indústrias Exportadoras de Madeira do Estado do Pará (AIMEX). A quebra de dormência foi realizada através da escarificação mecânica manualmente em lixa ( $\left.\mathrm{n}^{\circ} 120\right)$, na região oposta ao hilo da semente. Em seguida foram colocadas em água destilada por 24 horas, para embebição e posterior semeio. No momento do plantio, os tratamentos contendo os FMAs foram inoculados a partir da mistura de solo e raízes colonizadas $\left(50 \mathrm{~cm}^{3} \mathrm{vaso}^{-1}\right.$ de inóculo) com Rhizophagus clarus, Gigaspora margarita e inóculo misto (Rhizophagus clarus + Gigaspora margarita), deixando-se o tratamento-controle sem inoculação. Cada inóculo fúngico foi aplicado a uma profundidade aproximada de $5 \mathrm{~cm}$ nos vasos dos tratamentos correspondentes. Foram misturados de forma homogênea no substrato, procedendo-se em seguida a semeadura, colocando-se duas sementes por vaso, sendo feito o desbaste após duas semanas, deixando uma plântula por vaso. O experimento foi conduzido em casa de vegetação, utilizando-se o delineamento experimental inteiramente casualizados, em esquema fatorial 4 x 4, com a inoculação de fungos micorrízicos arbusculares: Rhizophagus clarus, Gigaspora margarita, inóculo misto e controle (sem FMAs); quatro doses de fósforo (P): 0, 60, 120 e $180 \mathrm{mg} \mathrm{dm}^{-3} \mathrm{de}$ solo, com quatro repetições. As doses de P foram escolhidas com base no trabalho de Vieira et al. (2006).

A colheita das plantas foi realizada aos 75 dias após o plantio. Após a coleta da parte aérea, as raízes foram retiradas e lavadas com água corrente, das quais foram coletadas amostras de raízes mais finas 
para determinação da porcentagem de colonização micorrízica. A parte aérea e a raiz foram acondicionadas individualmente em sacos de papel, para posterior quantificação da matéria seca da parte aérea e raiz e dos conteúdos de nitrogênio $(\mathrm{N})$, fósforo $(\mathrm{P})$, potássio $(\mathrm{K})$, cálcio $(\mathrm{Ca})$ e magnésio $(\mathrm{Mg})$. Para a determinação dos conteúdos de $\mathrm{N}$, o material vegetal foi submetido à digestão sulfúrica, na qual o nitrogênio foi determinado pelo método de Nessler (JACKSON, 1965). Os conteúdos de P, K, Ca e Mg foram determinados usando plasma (ICPE-9000) da marca Shimadzu, após digestão com $\mathrm{HNO}_{3}$ e $\mathrm{H}_{2} \mathrm{O}_{2}$, em sistema de digestão aberta (PETERS, 2005).

Para a avaliação da porcentagem da colonização micorrízica, as raízes foram lavadas e amostras de $2 \mathrm{~g}$ de raízes finas foram armazenadas em álcool etílico $50 \%$. Essas raízes foram utilizadas na determinação da porcentagem de colonização micorrízica, de acordo com a metodologia descrita por Grace e Stribley (1991). A marcha analítica constou das seguintes etapas: $1^{\circ}$ passo: imersão em KOH (10\%) duas vezes consecutivas, por 10 minutos cada, a $80^{\circ} \mathrm{C}$ em banho-maria e lavadas com água destilada; $2^{\circ}$ passo: imersão em água oxigenada alcalina $\left(\mathrm{H}_{2} \mathrm{O}_{2}\right)$, por 30 minutos e posterior lavagem em água destilada; $3^{\circ}$ passo: imersão em ácido clorídrico (5\%), durante 5 minutos; e $4^{\circ}$ passo: imersão em azul de tripano $(0,05 \%)$ (PHILLIPS; HAYMAN, 1970), durante 20 minutos a $80^{\circ} \mathrm{C}$. Os segmentos de raízes coloridas foram depositados com o auxílio de uma pinça sobre lâminas, sendo adicionadas algumas gotas de glicerol ácido sobre as raízes, sendo posteriormente cobertas por uma lamínula. O percentual de colonização foi avaliado microscópio para verificação da presença de estruturas de FMAs.

Os dados experimentais obtidos foram submetidos à análise de variância, utilizando-se o programa SANEST (ZONTA et al., 1984). Utilizou-se análise de regressão polinomial para os dados quantitativos e o teste de Tukey a $5 \%$ de probabilidade para os dados qualitativos.

\section{RESULTADOS E DISCUSSÃO}

Foi verificado efeito significativo $(p>0,05)$ das interações entre as espécies de fungos e doses de $\mathrm{P}$ para todas as variáveis de crescimento (Figuras 1, 2, 3, 4 e 5) e conteúdos de $\mathrm{P}, \mathrm{K}, \mathrm{Ca}$ e $\mathrm{Mg}$ na parte aérea (Figuras 7, 8,9 e 10), com exceção do conteúdo de $\mathrm{N}$ que não foi significativo. A porcentagem da colonização micorrízica foi influenciada pelas espécies de FMAs independente das doses de P no solo (Figura 6).

$\mathrm{Na}$ ausência da adubação fosfatada, a altura das mudas de paricá nos tratamentos inoculados com Rhizophagus clarus e inóculo misto foram 29,1 e 19,9\%, respectivamente, superiores à altura obtida no tratamento-controle. Entretanto, nas mudas inoculadas com Gigaspora margarita, os valores foram 18\% menores em relação ao controle (Figura 1). Vários estudos relataram o benefício dos FMAs em condições de baixa disponibilidade de nutrientes no solo, principalmente o fósforo (MARTINS et al., 2000; JACKSON et al., 2002; SMITH; READ, 2008; BALOTA et al., 2011). Segundo Smith et al. (2011), a associação micorrízica pode variar de acordo com cada espécie de planta e de FMAs de modo positivo ou negativo, em casos negativos, o fungo micorrízico pode consumir o carbono assimilado pela planta levando ao menor crescimento desta conforme o resultado deste trabalho para Gigaspora margarita.

Quando foi adicionado P ao solo, as mudas inoculadas com Gigaspora margarita atingiram valor máximo de $58 \mathrm{~cm}$ de altura na dose estimada de $112,9 \mathrm{mg} \mathrm{dm}^{-3}$. Observou-se também que a altura das mudas de paricá inoculadas com Rhizophagus clarus foram menores com a aplicação de doses crescentes de fósforo ao solo até a dose estimada em 103,2 $\mathrm{mg} \mathrm{dm}^{-3}$ (Figura 1). Estes resultados evidenciam o comportamento inverso entre as espécies de FMAs, ou seja, enquanto o Rhizophagus clarus apresentou menor influência sobre o crescimento das mudas em doses intermediárias, foi nessa condição que a Gigaspora margarita teve sua melhor resposta. Por outro lado, a utilização simultânea das duas espécies de FMAs (inóculo misto) proporcionou maior crescimento das mudas, independentemente da aplicação ou não de $\mathrm{P}$ ao solo, em relação ao controle. Segundo Rocha et al. (2006), esse comportamento está relacionado ao fato de os FMA promoverem maiores benefícios em baixa disponibilidade de $\mathrm{P}$, contrariamente, em condições de maior disponibilidade desse nutriente, ocorre a redução dos efeitos benéficos do fungo e passa a ser dispensável à planta.

Para a produção de matéria seca da parte aérea (MSPA), observou-se que as mudas colonizadas por Rhizophagus clarus e inóculo misto, na ausência de adubação com $\mathrm{P}$, foram maiores com incrementos de 25 


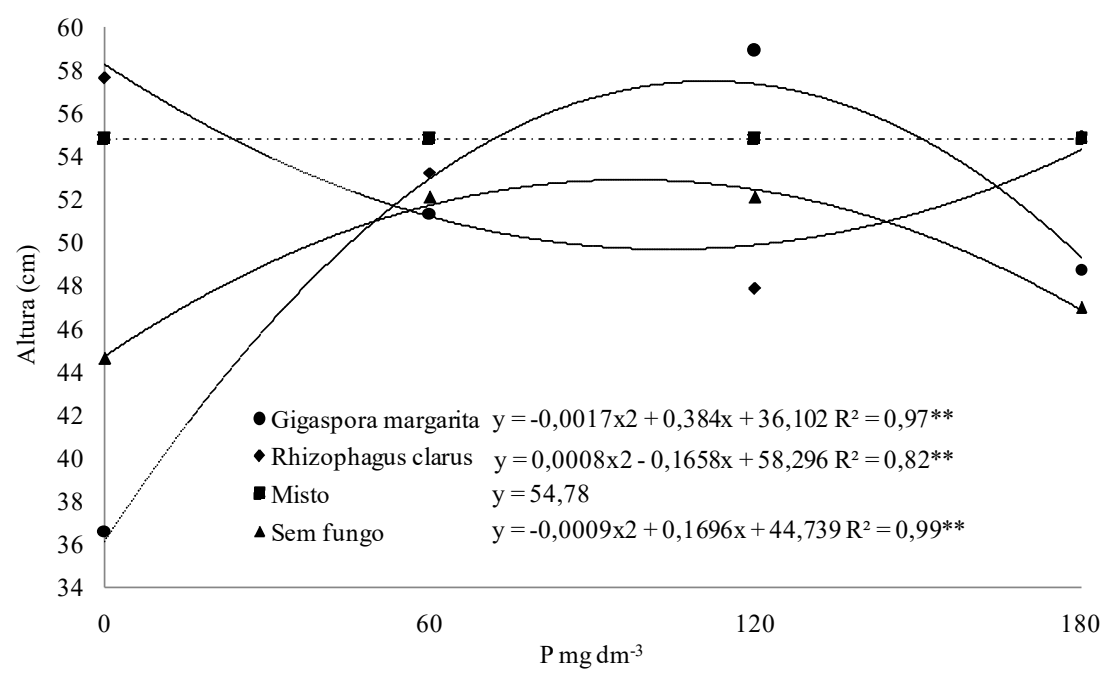

FIGURA 1: Altura das mudas de paricá em função dos fungos micorrízicos arbusculares (FMAs) e adubação fosfatada, aos setenta e cinco dias após a semeadura. C.V. $=3,23 \%$.

FIGURE 1: Height of paricá seedlings in function of arbuscular mycorrhizal fungi (AMF) and phosphate fertilization, at the age of seventy-five days after sowing. C.V. $=3.23 \%$.

e 37\%, respectivamente, em relação ao controle. As mudas inoculadas com Gigaspora margarita atingiram o ponto de máximo em 17,6 $\mathrm{g}_{\text {planta }}{ }^{-1}$, na dose estimada de $112,9 \mathrm{mgdm}^{-3} \mathrm{de} \mathrm{P}$ (Figura 2).

Os resultados obtidos no presente estudo evidenciam incremento na produção de matéria seca, através das doses de $\mathrm{P}$ e dos tratamentos microbiológicos, em mudas de paricá. O maior acúmulo de biomassa vegetal pode estar relacionado ao papel fisiológico do fósforo na planta proporcionando o aumento na produção de matéria seca (MARSCHNER, 1995). Aguiar et al. (2004), trabalhando com mudas de algaroba

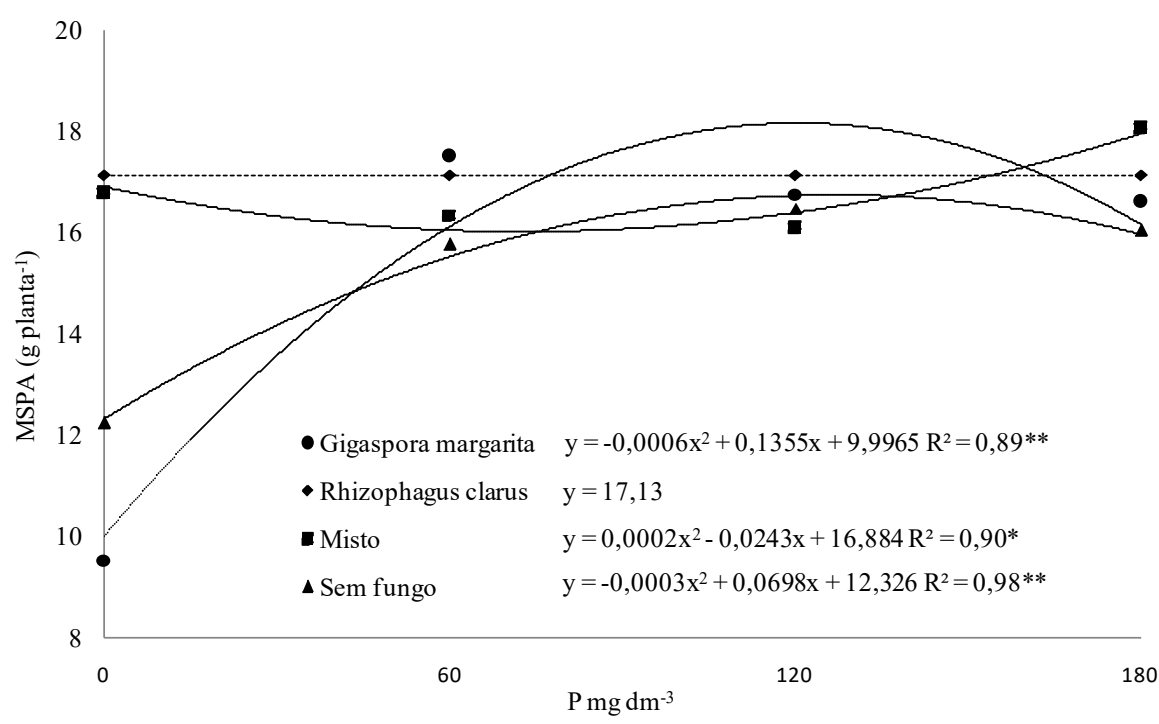

FIGURA 2: Matéria seca da parte aérea (MSPA) das mudas de paricá em função dos fungos micorrízicos arbusculares (FMAs) e adubação fosfatada, aos setenta e cinco dias após a semeadura. C.V.= $7,4 \%$.

FIGURE 2: Shoots dry matter of (ASDM) of paricá seedlings in function of arbuscular mycorrhizal fungi (AMF) and phosphate fertilization, at the age of seventy-five days after sowing. C.V. $=7.4 \%$. 
(Prosopis juliflora) em solo esterilizado, observaram interação entre as espécies introduzidas de FMAs e a adição de fósforo, o que favoreceu a produção de matéria seca. Outros estudos, com espécies arbóreas nativas de áreas tropicais em fase de crescimento inicial, também demonstraram efeito positivo dos FMAs na produção de matéria seca (POUYU-ROJAS et al., 2006; LACERDA et al., 2011).

$\mathrm{Na}$ ausência da adubação com P, as plantas não inoculadas (controle) e inoculadas com Gigaspora margarita apresentaram menor área foliar (Figura 3). Contudo, verificou-se um incremento de 49 e $75 \%$

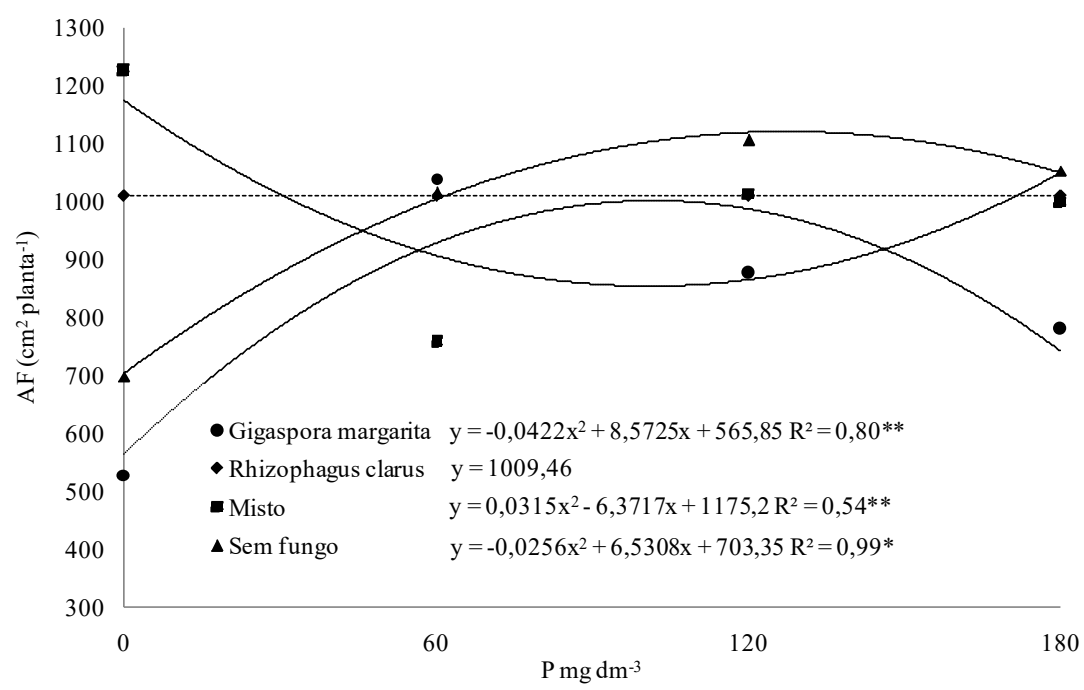

FIGURA 3: Área foliar (AF) das mudas de paricá em função dos fungos micorrízicos arbusculares (FMAs) e adubação fosfatada, aos setenta e cinco dias após a semeadura. C.V. $=12,5 \%$.

FIGURE 3: Leaf area (LA) of paricá seedlings in function of arbuscular mycorrhizal fungi (AMF) and phosphate fertilization, at the age of seventy-five days after sowing. C.V.= $12.5 \%$.

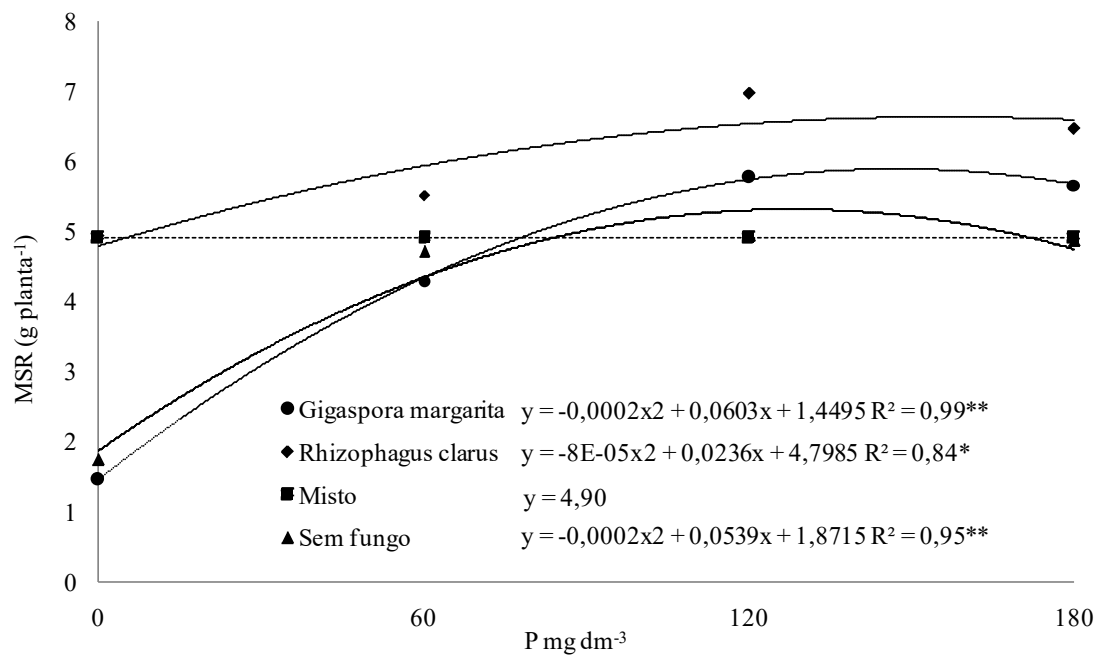

FIGURA 4: Matéria seca da raiz (MSR) das mudas de paricá em função dos fungos micorrízicos arbusculares (FMAs) e adubação fosfatada, aos setenta e cinco dias após a semeadura. C.V. $=9,05 \%$.

FIGURE 4: Root dry matter (RDM) of paricá seedlings in function of arbuscular mycorrhizal fungi (AMF) and phosphate fertilization, at the age of seventy-five days after sowing. C.V. $=9.05 \%$. 
na área foliar nas mudas micorrizadas com a espécie Rhizophagus clarus e o inóculo misto em relação ao controle, respectivamente. Esses resultados corroboram com os de Santos et al. (2008), que obtiveram maior área foliar devido a micorrização em espécies nativas. A medida da área foliar é importante e pode auxiliar no estudo do crescimento e desenvolvimento das plantas (ENGIN; ENGIN, 2013).

A matéria seca da raiz (MSR) das mudas inoculadas com o Rhizophagus clarus e inóculo misto, na ausência de adubação fosfatada, apresentou incremento de 188 e $182 \%$, respectivamente, em relação ao controle, sendo que a espécie Gigaspora margarita não promoveu incremento na MSR, sendo inferior ao controle (Figura 4). De acordo com Lacerda et al. (2011), o maior desenvolvimento radicular de mudas arbóreas auxilia no estabelecimento em condições de campo. Os mesmos autores observaram em mudas de caroba (Jacaranda cuspidifolia), gabiroba (Campomanesia cambessedeana), ingá (Inga laurina) e chichá (Sterculia striata) efeito sinérgico da inoculação de Rhizophagus clarus e aplicação de P, para a variável matéria seca de raízes, corroborando os resultados encontrados nesse estudo.

Para a variável diâmetro, as mudas micorrizadas com a espécie Rhizophagus clarus e o inóculo misto na ausência da adubação fosfatada proporcionaram incremento de 27,1 e $15,7 \%$, respectivamente, em relação ao controle. Entretanto, com incremento das doses de P no solo não foi observado efeito significativo para essas espécies de fungos. Observou-se, ainda, menor diâmetro das mudas inoculadas com Gigaspora margarita em relação ao controle na ausência da adubação fosfatada. O ajuste ao modelo de regressão, para o diâmetro do coleto em função das doses de fósforo, apresentou uma tendência linear com aumentos para as mudas inoculadas com Gigaspora margarita e o controle (Figura 5). Mudas de algaroba (Prosopis juliflora) também apresentaram aumento no diâmetro do coleto, quando inoculadas com FMAs em solo esterilizado em relação àquelas não inoculadas, sem ou com adição de $\mathrm{P}$ (AGUIAR et al., 2004). Trabalhos realizados por Vieira et al. (2006) e Viégas et al. (2007) evidenciaram que mudas de paricá adubadas com $\mathrm{P}$ apresentaram maior incremento para a variável diâmetro.

A porcentagem de colonização micorrízica nas raízes das mudas de paricá foram influenciadas pelas espécies de FMAs independentemente das doses de P no solo (Figura 6). Observou-se que a espécie Gigaspora margarita, quando inoculada separadamente, apresentou as menores porcentagens de colonização micorrízica, apenas $20 \%$ em comparação aos demais tratamentos fúngicos. Entretanto, quando combinada com o Rhizophagus clarus (inóculo misto), resultou na maior porcentagem de colonização micorrízica, não diferindo do Rhizophagus clarus separadamente (Figura 6). Resultados diferentes foram encontrados por Caldeira et al. (1997), esses autores observaram em mudas de Copaifera martii maior porcentagem de colonização micorrízica em mudas inoculadas Gigaspora margarita e Rhizophagus clarus, separadamente,

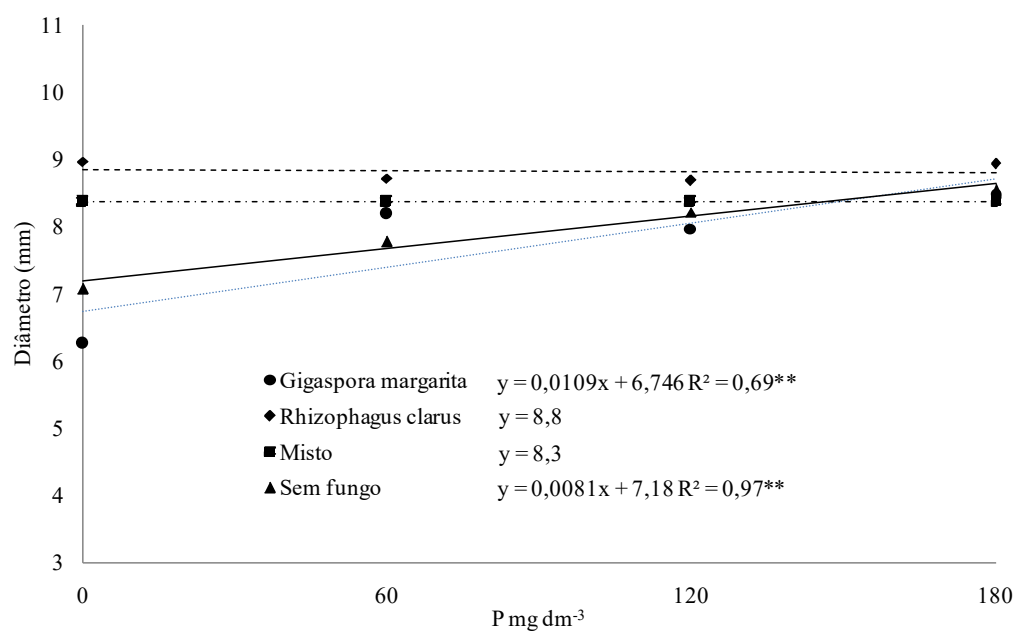

FIGURA 5: Diâmetro das mudas de paricá em função dos fungos micorrízicos arbusculares (FMAs) e adubação fosfatada, aos setenta e cinco dias após a semeadura. C.V. $=4,7 \%$.

FIGURE 5: Diameter of paricá seedlings in function of arbuscular mycorrhizal fungi (AMF) and phosphate fertilization, at the age of seventy-five days after sowing. C.V. $=4.7 \%$. 
demonstrando que o benefício dos FMAs depende da espécie de planta em estudo e das espécies de FMAs, além das condições edafoclimáticas.

As doses de $\mathrm{P}$ aplicadas ao substrato não influenciaram na porcentagem de colonização micorrízica, que apresentaram alta colonização mesmo em altos níveis de $\mathrm{P}$, evidenciando a possibilidade da utilização desses fungos em programas de adubação para melhorar a qualidade da muda. Certas espécies de fungos podem possuir grande capacidade para colonizar as plantas, mas a proporção de hifas externas varia muito entre as espécies, provavelmente, para o paricá, a sinalização para a colonização não seja a quantidade de P na solução solo. Resultados semelhantes foram encontrados por Lacerda et al. (2011), trabalhando com plantas arbóreas, verificaram aumento na porcentagem de colonização micorrízica decorrente da inoculação com Rhizophagus clarus, sendo que não houve efeito do fósforo no solo sobre a colonização micorrízica. Flores-Aylas et al. (2003), trabalhando com mudas de fedegoso (Senna macranthera), cássia-verrugosa (Senna multijuga) e aroeira (Schinus terebenthifolius), também não observaram efeito das doses de P sobre a colonização micorrízica.

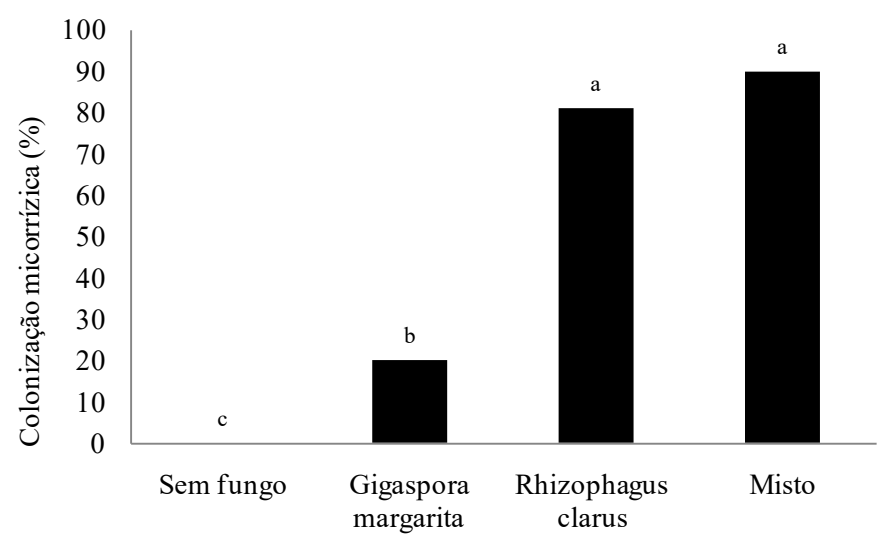

FIGURA 6: Colonização micorrízica em raízes de mudas de paricá aos setenta e cinco dias após a semeadura. Médias seguidas pela mesma letra não diferem entre si, pelo teste de Tukey em nível de probabilidade de $5 \%$. C.V. $=29,1 \%$.

FIGURE 6: Mycorrhizal colonization in roots of paricá seedlings at seventy-five days after sowing. Bars followed by the same letter not differ by Tukey test at $5 \%$ probability level. C.V. $=29.1 \%$.

O conteúdo dos nutrientes da parte aérea expressa a capacidade dos FMAs em promover o aumento na absorção de nutrientes do solo. O conteúdo de $\mathrm{N}$ da parte aérea das mudas de paricá não foi influenciado nem pela inoculação com os FMAs nem pelas doses de P. Entretanto, a translocação de nitrogênio pelo fungo pode representar um incremento significativo na absorção de $\mathrm{N}$ pela planta, como demonstrado por Tanaka e Yano (2005). O conteúdo de P na parte aérea aumentou linearmente em resposta às doses P e FMAs (Figura 7). As mudas micorrizadas, na ausência da adubação fosfatada, apresentaram maior conteúdo de $\mathrm{P}$ em relação ao controle. As mudas inoculadas com Gigaspora margarita, Rhizophagus clarus e o inóculo misto, promoveram incremento no conteúdo de $\mathrm{P}$ de 21,37; 229,42 e 284,41\%, respectivamente, em relação ao controle, quando não foi realizada a adubação fosfatada. Dessa forma, pode-se considerar que a associação dos FMAs com as mudas de paricá foi efetiva para absorção desse nutriente. Estes resultados corroboram com Schiavo e Martins (2003), os quais verificaram que os FMAs proporcionaram incrementos nos conteúdos de $\mathrm{P}$ da parte aérea das mudas de acácia (Acacia mangium), mesmo quando o substrato apresentou elevados teores de P. Vários trabalhos demonstraram que as espécies arbóreas nativas em estádio inicial de crescimento, quando micorrizadas apresentaram maior absorção de P (FLORES-AYLAS et al., 2003; SCHIAVO et al., 2009; LACERDA et al., 2011). Estes resultados indicam a capacidade dos FMAs em aumentar o conteúdo de $\mathrm{P}$ da parte aérea das mudas de paricá podendo ser utilizados para a produção de mudas a fim de reduzir os gastos com adubação fosfatada, e ainda proporcionar melhores condições de 


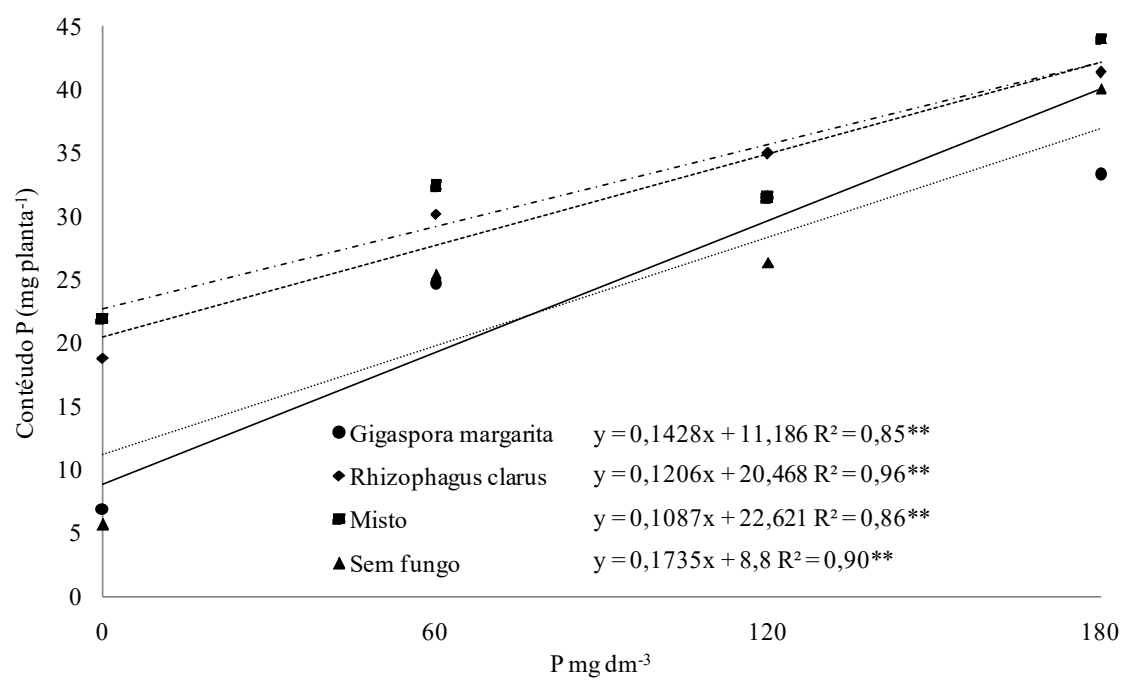

FIGURA 7: Conteúdo de P das mudas de paricá em função dos fungos micorrízicos arbusculares (FMAs) e adubação fosfatada, aos setenta e cinco dias após a semeadura. C.V. $=12,2 \%$.

FIGURE 7: $\mathrm{P}$ contents in paricá seedling in function of arbuscular mycorrhizal fungi (AMF) and phosphate fertilization, at the age of seventy-five days after sowing. C.V. $=12.2 \%$.

sobrevivências das mudas a campo, devido às grandes adversidades, especialmente em condições de baixas concentrações de P no solo.

As espécies Rhizophagus clarus e o inóculo misto, na ausência de $\mathrm{P}$, apresentaram incremento de 26,7 e 30,9\% para conteúdo de K, respectivamente, em relação ao controle (Figura 8). Esses resultados demonstram que os FMAs também contribuem para a maior aquisição de outros nutrientes pelas plantas, além do P. Resultados semelhantes foram obtidos por Lima e Souza (2014), nos quais foram observados incrementos significativos no conteúdo de $\mathrm{K}$ na parte aérea das mudas clonais de eucaliptos inoculadas com FMAs, em relação às mudas não inoculadas. Apenas as mudas inoculadas com Gigaspora margarita

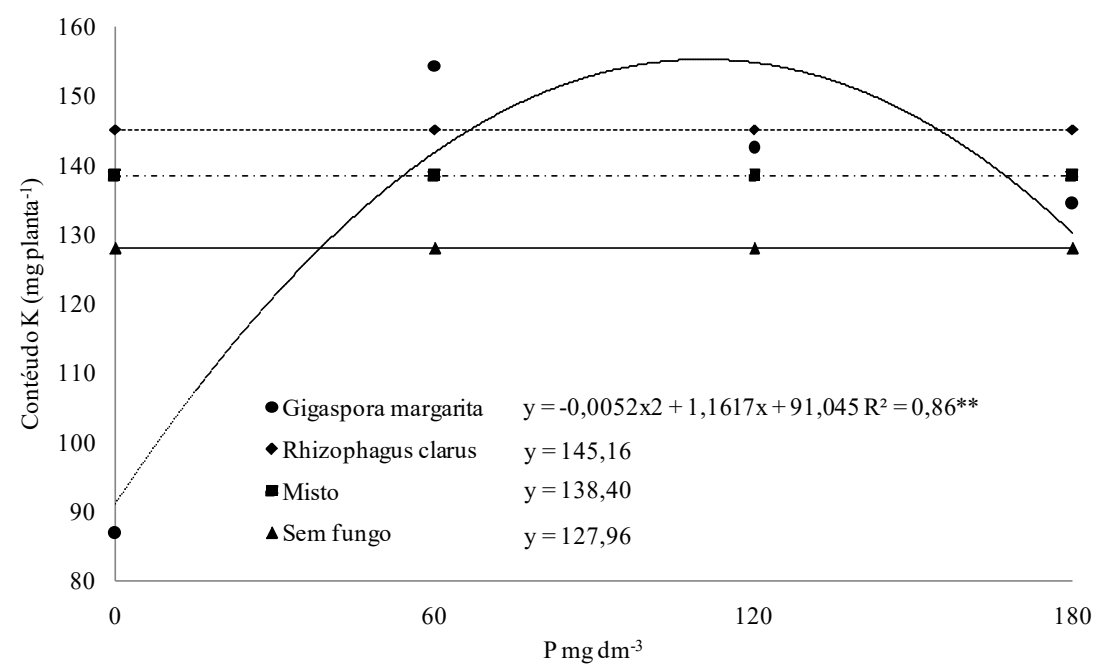

FIGURA 8: Conteúdo de $\mathrm{K}$ das mudas de paricá em função dos fungos micorrízicos arbusculares (FMAs) e adubação fosfatada, aos setenta e cinco dias após a semeadura. C.V.=13,09\%.

FIGURE 8: K content in paricá seedling in function of arbuscular mycorrhizal fungi (AMF) and phosphate fertilization, at the age of seventy-five days after sowing. C.V. $=13.09 \%$. 
apresentaram comportamento quadrático para o conteúdo de $\mathrm{K}$, em relação às doses de $\mathrm{P}$ aplicadas ao substrato. De acordo com Marshner e Dell (1994), as hifas fúngicas são capazes de absorver e transportar $\mathrm{K}$ para o hospedeiro proporcionando melhores condições nutricionais.

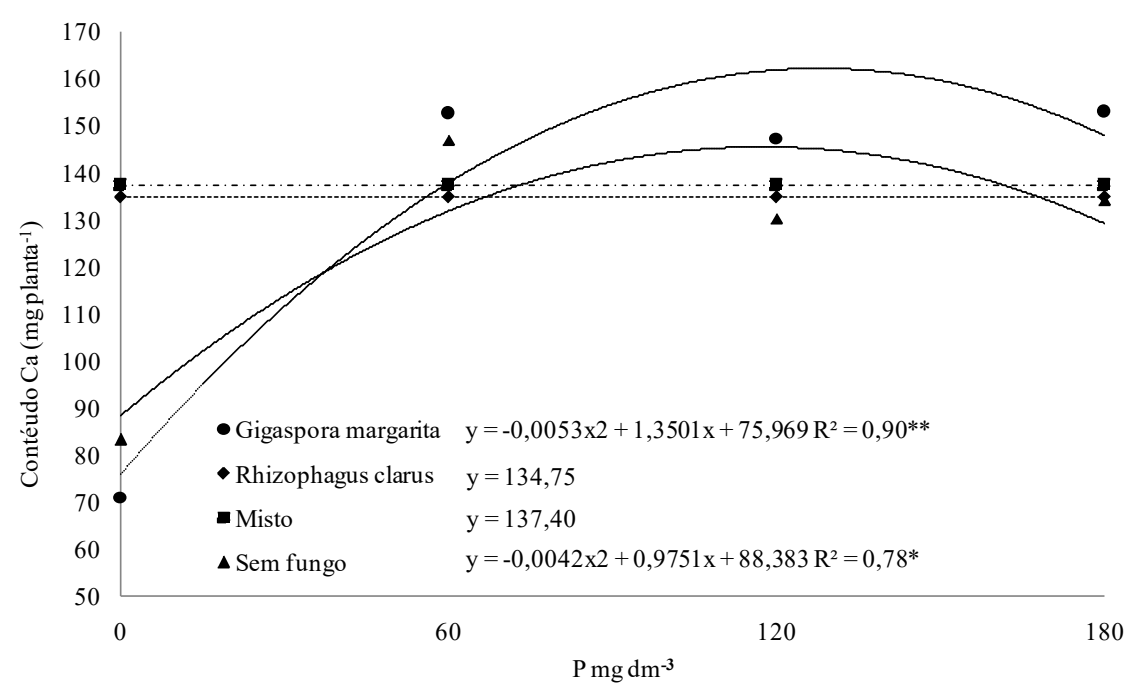

FIGURA 9: Conteúdo de Ca das mudas de paricá em função dos fungos micorrízicos arbusculares (FMAs) e adubação fosfatada, aos setenta e cinco dias após a semeadura. C.V.=17,7\%.

FIGURE 9: Ca content in paricá seedling in function of arbuscular mycorrhizal fungi (AMF) and phosphate fertilization, at the age of seventy-five days after sowing. C.V.=17.7\%.

Com relação ao conteúdo de $\mathrm{Ca}$, o fungo Rhizophagus clarus e o inóculo misto, na ausência de $\mathrm{P}$, promoveram incrementos de 60 e $89,16 \%$, respectivamente, em relação ao controle (Figura 9). A capacidade dos FMAs em proporcionar maior acúmulo de nutrientes, como o cálcio, na ausência de adubação fosfatada foi evidenciada por Pouyú-Rojas e Siqueira (2000), em mudas de espécies nativas da Mata Atlântica. Os mesmos autores também observaram que, em condições de adubação fosfatada, houve o aumento na

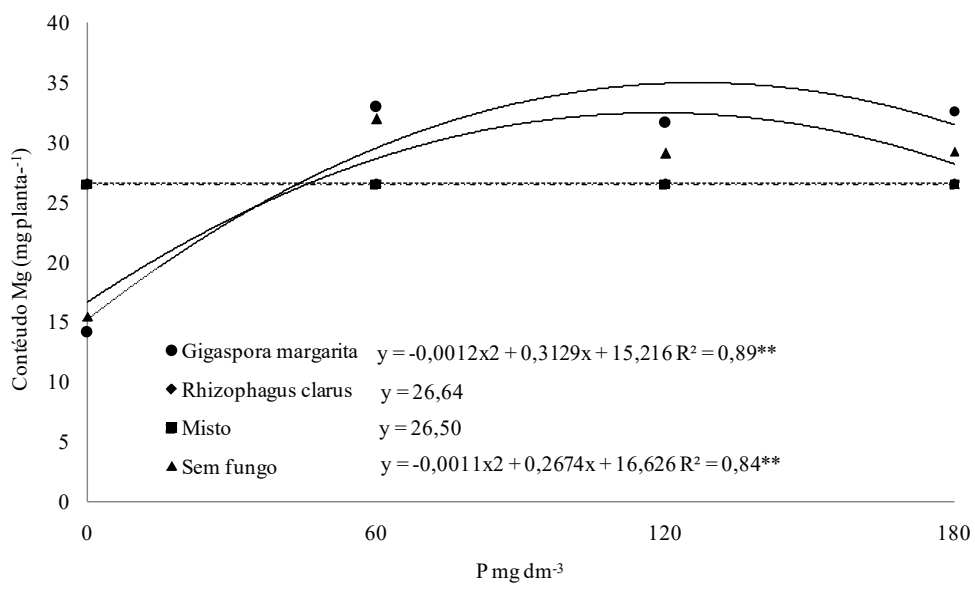

FIGURA 10: Conteúdo de Mg das mudas de paricá em função dos fungos micorrízicos arbusculares (FMAs) e adubação fosfatada, aos setenta e cinco dias após a semeadura. C.V. $=18,2 \%$

FIGURE 10: Mg content in paricá seedling in function of arbuscular mycorrhizal fungi (AMF) and phosphate fertilization, at the age of seventy-five days after sowing. C.V. $=18.2 \%$. 
aquisição de Ca. Sendo assim, os FMAs são uma potencial alternativa para a produção de mudas com maior capacidade em absorver nutrientes essenciais, como o $\mathrm{Ca}$, para o crescimento e o metabolismo vegetal.

$\mathrm{O}$ conteúdo de $\mathrm{Mg}$ da parte aérea das mudas de paricá, na ausência de adubação fosfatada, foram 46,4 e 76,1\% maior nas mudas inoculadas com as espécies Rhizophagus clarus e o inóculo misto, respectivamente, em relação ao tratamento-controle (Figura 10). Entretanto, quando as mudas foram submetidas à adubação com $120 \mathrm{mg} \mathrm{dm} 3$ de $\mathrm{P}$ e inoculadas com Gigaspora margarita, apresentaram o maior conteúdo de $\mathrm{Mg}$ (35 mg planta $\left.{ }^{-1}\right)$ na massa seca da parte aérea. Esses resultados indicam a importância de se avaliar diferentes espécies de FMAs e doses de fósforo no crescimento e acúmulo de nutrientes, pois esta associação é de baixa especificidade, podendo ainda sofrer influências das diversas condições ambientais (SMITH; READ, 2008).

Com relação às mudas não inoculadas pode-se observar a necessidade da adubação fosfatada para o acúmulo de $\mathrm{Mg}$ na matéria seca da parte área, o que evidencia a importância desse nutriente para o crescimento vegetal.

\section{CONCLUSÕES}

A inoculação dos FMAs proporciona maior crescimento e maior acúmulo de $\mathrm{P}, \mathrm{K}, \mathrm{Mg}$ e Ca na parte área das mudas de paricá em relação ao controle, com destaque para a inoculação com o FMA Rhizophagus clarus e inóculo misto (Rhizophagus clarus + Gigaspora margarita).

As mudas de paricá podem ser produzidas em substratos contendo FMAs para obter mudas com melhor estado nutricional e crescimento, sem necessidade da adubação fosfatada, sendo uma alternativa viável para produção de mudas que serão utilizadas em projetos de reflorestamentos.

\section{AGRADECIMENTOS}

Ao Conselho Nacional de Desenvolvimento Científico e Tecnológico (CNPq) pela concessão de bolsa de mestrado do primeiro autor.

\section{REFERÊNCIAS}

AGUIAR, R. L. F. D. et al. Interação entre fungos micorrízicos arbusculares e fósforo no desenvolvimento da algaroba [Prosopis juliflora (SW) DC]. Revista Árvore, Viçosa, MG, v. 28, n. 4, p. 589-598, 2004.

BALOTA, E. L.; MACHINESKI, O.; STENZEL, N. M. C. Resposta da acerola à inoculação de fungos micorrízicos arbusculares em solo com diferentes níveis de fósforo. Bragantia, Campinas, v. 70, n. 1, p. 166-175, 2011.

BAREA, J. M. et al. Arbuscular mycorrhizas and their significance in promoting soil-plant systems sustainability against environmental stresses. In: GONZÁLEZ, M. B. R.; GONZÁLEZ-LÓPEZ, J. (Ed.). Beneficial plant-microbial interactions: ecology and applications. Boca Raton: CRC Press, 2013. p. 353387.

BECKER, W. N.; HALL, I. R. Gigaspora margarita, a new species in the Endogonaceae. Mycotaxon, Ithaca, v. 4, n. 1, p. 155-160, 1976.

BRASIL. Lei ${ }^{\circ}$ 6.938, de 31 de agosto de 1981. Dispõe sobre a Política Nacional do Meio Ambiente, seus fins e mecanismos de formulação e aplicação, e dá outras providências. Diário Oficial da União, Brasília, 2 set. 1981.

BRIENZA JÚNIOR, S. et al. Recuperação de áreas degradadas com base em sistema de produção florestal energético-madeireiro: indicadores de custos, produtividade e renda. Revista Amazônia Ciência e Desenvolvimento, Belém, v. 4, n. 7, 2008.

CALDEIRA, M. V. W. et al. Crescimento de leguminosas arbóreas em resposta a inoculação com fungos micorrízicos arbusculares. Ciência Florestal, Santa Maria, v. 7, n. 1, p. 1-10, 1997.

CARNEIRO, R. F. V. et al. Inoculação micorrízica arbuscular e adubação fosfatada no cultivo de forrageiras consorciadas. Archivos Zootecnia, Córdoba, v. 60, n. 232, p. 1191-1202, 2011. 
ENGIN, D.; ENGIN, M. Design of a Plant Leaf Area Meter Using PV Cell and Embedded Microcontroller. Advances in Materials Science and Engineering, Boca Raton, v. 2013, 2013.

FARIAS, T. M. et al. Micorrização e crescimento de progênies de Hymenaea stignocarpa Mart. ex. Hayne em subsolo de área degradada. Ciência Florestal. Santa Maria, v. 23, n. 1, p. 233-243, 2013.

FLORES-AYLAS, W. W. et al. Efeito de Glomus etunicatum e fósforo no crescimento inicial de espécies arbóreas em semeadura direta. Pesquisa Agropecuária Brasileira, Brasília, v. 38, n. 2, p. 257-266, 2003. GONDIN, J. C. et al. Emergência de plântulas de Schizolobium amazonicum Huber ex Ducke (CAESALPINACEAE) em diferentes substratos e sombreamento. Revista Ciência Agronômica, Fortaleza, v. 46, n. 2, p. 329-338, 2015.

GRACE, C.; STRIBLEY, D. P. A safer procedure for roution staining of vesicular-arbuscular mycorrhizal fungi. Mycological Research, Cambridge, v. 95, n. 10, p. 1160-1162, 1991.

INSTITUTO DO HOMEM E MEIO AMBIENTE DA AMAZÔNIA. [Home page]. Disponível em: <http:// www.imazon.org.br/>. Acesso em: 2011.

JACKSON, L. E.; MILLER, D.; SMITH, S. E. Arbuscular mycorrhizal colonization and growth of wild and cultivated lettuce in response to nitrogen and phosphorus. Scientia Horticulturae, Amsterdam, v. 94, n. 3, p. 205-218, 2002.

JACKSON, M. L. Soil chemical analysis. 5. ed. Englewood Cliffs: Prentice-Hall, 1965. 498 p.

LACERDA, K. A. P. et al. Fungos micorrízicos arbusculares e adubação fosfatada no crescimento inicial de seis espécies arbóreas do Cerrado. Cerne, Lavras, v. 17, n. 3, p. 377-386, 2011.

LEÃO, N. V. M. et al. Biometria e diversidade de temperaturas e substratos para a viabilidade de sementes de ipê amarelo. Informativo ABRATES, Londrina, v. 25, n. 1, p. 50-54, 2015.

LIMA, F. S.; SOUSA, C. S. Crescimento e nutrição de mudas de clones de eucalipto inoculadas com fungos micorrízicos. Pesquisa Agropecuária Tropical, Goiânia, v. 2, n. 1, p. 110-118, 2014.

LUNZ, A. M. et al. Ocorrência de Pantophthalmus kerteszianus e P. chuni (Diptera: Pantophthalmidae) em paricá, no Estado do Pará. Revista Pesquisa Florestal Brasileira, Colombo, v. 30, n. 61, p. 71-74, 2010. MARSCHNER, H. Mineral nutrition of higher plants. San Diego: Academic Press, 1995. 889 p.

MARSCHNER, H.; DELL, B. Nutrient uptake in mycorrhizal symbiosis. Plant and Soil, The Hague, V. 159 , n. 1, p. 89-102, 1994.

MARTINS, M. A.; GONÇALVES, G. F.; SOARES, A. C. F. Efeito de fungos micorrízicos arbusculares associados a compostos fenólicos, no crescimento de mudas de mamoeiro. Pesquisa Agropecuária Brasileira, Brasília, v. 35, n. 7, p. 1465-1471, 2000.

MOREIRA, F. M. S.; SIQUEIRA, J. O. Microbiologia e bioquímica do solo. Lavras: UFLA, 2006. 729 p. NADEEM, S. M. et al. The role of mycorrhizae and plant growth promoting rhizobacteria (PGPR) in improving crop productivity under stressful environments. Biotechnology advances, New York, v. 32, n. 2, p. 429-448, 2014.

PETERS, J. B. Wisconsin procedures for soil testing, plant analysis and feed \& forage analysis: plant analysis. Madison: College of Agriculture and Life Sciences, University of Wisconsin-Extension, 2005.

PHILLIPS, J. M.; HAYMAN, D. S. Improved procedures for clearing roots and staining parasitic and vesicular-arbuscular mycorrhizal fungi for rapid assessment of infection. Transactions of the British Mycological Society, Cambridge, v. 55, p. 157-160, 1970.

POUYÚ-ROJAS, E. et al. Compatibilidade simbiótica de fungos micorrízicos arbusculares com espécies arbóreas tropicais. Revista Brasileira de Ciência do Solo, Viçosa, MG, n. 30, p. 413-424, 2006.

POUYÚ-ROJAS, E.; SIQUEIRA, J. O. Micorriza arbuscular e fertilização do solo no desenvolvimento pós-transplante de mudas de sete espécies florestais. Pesquisa Agropecuária Brasileira, Brasília, v. 35, n. 1, p. 103-114, 2000.

ROCHA, F. S. et al. Dependência e resposta de mudas de cedro a fungos micorrízicos arbusculares. Pesquisa Agropecuária Brasileira, Brasília, v. 41, n. 1, p. 77-84, 2006.

ROSA, L. S. Ecologia e silvicultura do paricá (Schizolobium amazonicum Huber ex. Ducke) na Amazônia brasileira. Revista de Ciências Agrárias, Belém, v. 45, p. 135-174, 2006.

SABOGAL, C. et al. Silvicultura na Amazônia Brasileira: avaliação de experiências e recomendações para implementação e melhoria de sistemas. Belém: CIFOR, 2006. 190 p.

SAMARÃO, S. S. et al. Desempenho de mudas de gravioleira inoculadas com fungos micorrízicos 
arbusculares em solo não-esterilizado, com diferentes doses de fósforo. Acta Scientiarum Agronomy, Maringá, v. 33, n. 1, p. 81-88, 2011.

SANTOS, J. G. D. et al. Eficiência de fungos micorrízicos arbusculares isolados de solos de áreas de mineração de bauxita no crescimento inicial de espécies nativas. Revista Brasileira de Ciência do Solo, Viçosa, MG, v. 32, p. 141-150, 2008.

SCHIAVO, J. A. et al. Avaliação nutricional de mudas de Acacia mangium, Sesbania virgata e Eucalyptus camaldulensis inoculadas com fungos micorrízicos, em casa de vegetação e em cava de extração de argila. Acta Scientiarum Agronomy, Maringá, v. 31, n. 4, p. 701-707, 2009.

SCHIAVO, J. A; MARTINS, M. A. Produção de mudas de acácia colonizadas com micorrizas e rizóbio em diferentes recipientes. Pesquisa Agropecuária Brasileira, Brasília, v. 38, n. 2, p. 173-178, 2003.

SCHUESSLER, A.; WALKER, C. The Glomeromycota: a species list with new families and genera. Edinburgh \& Kew: The Royal Botanic Garden; Munich: Botanische Staatssammlung Munich; Oregon: Oregon State University, 2010.

SMITH, S. E. et al. Roles of arbuscular mycorrhizas in plant phosphorus nutrition: interactions between pathways of phosphorus uptake in arbuscular mycorrhizal roots have important implications for understanding and manipulating plant phosphorus acquisition. Plant Physiology, New York, v. 156, n. 3, p. 1050-1057, 2011.

SMITH, S. E.; READ, D. J. Mycorrhizal Symbiosis. 3. ed. Califórnia: Academic Press, 2008. 605 p.

TANAKA, Y.; YANO, K. Nitrogen delivery to maize via mycorrhizal hyphae depends on the form of $\mathrm{N}$ supplied. Plant, Cell Environment, New York, v. 28, p. 1247-1254, 2005.

VIÉGAS, I. J. M. et al. Efeito da adubação NPK em plantas jovens de paricá. Belém: Embrapa Amazônia Oriental, 2007. 4 p. (Comunicado Técnico, 193).

VIEIRA, A. H et al. Crescimento de mudas de Schizolobium parahyba var. amazonicum (Huber ex Ducke) Barneby sob diferentes níveis de nitrogênio, fósforo e potássio. Porto Velho: Embrapa Rondônia, 2006. 17 p. (Boletim de Pesquisa e Desenvolvimento, 31).

WALDER, F. et al. Mycorrhizal networks: common goods of plants shared under unequal terms of trade. Plant physiology, New York, v. 159, n. 2, p. 789-797, 2012.

YANG, G. et al. The interaction between arbuscular mycorrhizal fungi and soil phosphorus availability influences plant community productivity and ecosystem stability. Journal of Ecology, London, v. 102, n. 4, p. 1072-1082, 2014.

ZONTA, E. P. Sistema de análises estatísticas para microcomputadores (SANEST). Pelotas: Universidade Federal de Pelotas, 1984. 151 p. 